serum insulin response and increased risk of Type 2 diabetes. Diabetes 52:573-577

8. Frayling TM, Hattersley AT, McCarthy A et al. (2002) A putative functional polymorphism in the IGF-1 gene. Diabetes 51:2313-2316

9. Winarto A, Miki T, Seino S, Iwanaga T (2001) Morphological changes in pancreatic islets of KATP channel-deficient mice: the involvement of KATP channels in the survival of insulin cells and the maintenance of islet architecture. Arch Histol Cytol 64:59-67

Corresponding author: A. T. Hattersley, Centre for Molecular Genetics, Peninsula Medical School, Barrack Road, Exeter, EX2 5AX, UK

\section{Lack of association between gene variants in the ALMS1 gene and Type 2 diabetes mellitus}

To the Editor: Recently the gene responsible for the Alström syndrome has been identified $[1,2]$. It was shown that mutations in this large gene, encoding for a protein of 4169 amino acids, associate with Alström syndrome cases. Alström syndrome is an autosomal recessive disease; characterized by retinitis pigmentosa, Type 2 diabetes mellitus, obesity and sensorineural deafness (OMIM 203800). Furthermore patients frequently have cardiomyopathy, insulin resistance and dyslipidaemia. Since many of these features are also seen in Type 2 diabetes mellitus patients this gene is a potential candidate gene for Type 2 diabetic patients and associating co-morbidities This led us to search for gene variants in the ALMS1 gene in Type 2 diabetes, obesity and insulin resistance.

DOI 10.1007/s00125-003-1138-0

Received: 24 February 2003 / Revised: 8 April 2003

Published online: 21 June 2003

(C) Springer-Verlag 2003
Association studies were carried out with Type 2 diabetic patients $(n=188)$ and age-matched normoglycaemic subjects $(n=167)$ randomly chosen from a population-based study in the Netherlands [3]. Glucose tolerance status was confirmed by OGTT in all subjects as described previously [3]. All participants were between 50 and 75 years and of Caucasian origin to avoid bias. Allele frequencies of gene variants in the ALMSI gene were compared between Type 2 diabetic subjects and matched controls using Fischer's exact tests. ANOVA or linear regression analysis was carried out to test associations with other diabetes related parameters like BMI, glucose and insulin concentrations. A $p$ value of 0.05 or less was considered statistically significant.

We carried out a database search to identify genetic variation in the coding region of the gene. Recently it has been shown that disease-associated gene variants are found more frequently in the coding regions of the gene compared to the non-coding regions [4]. Therefore we have limited our study to these gene variants. A total of 78 SNPs in the ALMS1 gene were described in the public SNP database which is available via the internet (http://www.ncbi.nlm.nih.gov/SNP/, Jan 2003). Seven of these were in the coding regions of the ALMS1 gene. Two of these seven gene variants were silent, Asn3815 (AAC-AAT) and Leu4060 (CTG-TTG). The other variants were at positions Gly673 (Gly-Val, GGA-GTA), Asp2674 (Asp-His, GAT-CAT), Asp2678 (Asp-Ala, GAC-GCC), Arg2828 (Arg-Ser, AGG-

Table 1. Clinical characteristics according to ALMSI genotype

\begin{tabular}{|c|c|c|c|c|c|c|c|c|}
\hline \multirow{2}{*}{$\frac{\text { Amino Acid }}{2674}$} & \multicolumn{3}{|l|}{ Type 2 DM } & \multirow[t]{2}{*}{$p$} & \multicolumn{3}{|l|}{ NGT } & \multirow[t]{2}{*}{$p$} \\
\hline & Asp/Asp & Asp/His & His/His & & Asp/Asp & Asp/His & His/His & \\
\hline$n$ & 118 & 61 & 6 & & 112 & $45^{1}$ & 3 & $0.43(0.23)^{\mathrm{a}}$ \\
\hline $\mathrm{FPG}(\mathrm{mmol} / \mathrm{l})$ & $7.85 \pm 0.27$ & $7.48 \pm 0.28$ & $7.37 \pm 1.04$ & 0.65 & $5.45 \pm 0.07$ & $5.37 \pm 0.11$ & $4.87 \pm 0.27$ & 0.34 \\
\hline $2 \mathrm{~h}$ glucose $(\mathrm{mmol} / \mathrm{l})$ & n.a. & n.a. & n.a. & & $5.36 \pm 0.17$ & $5.45 \pm 0.16$ & $5.17 \pm 1.05$ & 0.88 \\
\hline FPI (pmol/l) & $15.2 \pm 1.3$ & $16.8 \pm 1.8$ & $21.3 \pm 5.0$ & 0.07 & $13.8 \pm 0.7$ & $14.3 \pm 1.0$ & $9.0 \pm 0.2$ & 0.29 \\
\hline 2828 & Arg/Arg & Arg/Ser & Ser/Ser & & Arg/Arg & Arg/Ser & Ser/Ser & \\
\hline$n$ & 114 & 63 & 7 & & 98 & 54 & 12 & $0.37(0.41)^{\mathrm{a}}$ \\
\hline BMI $\left(\mathrm{kg} / \mathrm{m}^{2}\right)$ & $28.9 \pm 0.5$ & $28.0 \pm 0.5$ & $30.1 \pm 2.2$ & 0.51 & $26.2 \pm 0.3$ & $26.3 \pm 0.4$ & $25.1 \pm 1.0$ & 0.36 \\
\hline $\mathrm{FPG}(\mathrm{mmol} / \mathrm{l})$ & $7.58 \pm 0.23$ & $7.73 \pm 0.34$ & $9.86 \pm 2.10$ & 0.07 & $5.34 \pm 0.05$ & $5.58 \pm 0.14$ & $5.32 \pm 0.18$ & 0.12 \\
\hline $2 \mathrm{~h}$ glucose $(\mathrm{mmol} / \mathrm{l})$ & n.a. & n.a. & n.a. & & $5.27 \pm 0.11$ & $5.58 \pm 0.32$ & $5.56 \pm 0.30$ & 0.50 \\
\hline FPI (pmol/l) & $16.5 \pm 1.3$ & $13.3 \pm 0.8$ & $12.3 \pm 2.7$ & 0.31 & $13.5 \pm 0.7$ & $14.8 \pm 0.8$ & $12.0 \pm 1.5$ & 0.49 \\
\hline $\mathrm{FPG}(\mathrm{mmol} / \mathrm{l})$ & $8.42 \pm 0.64$ & $7.33 \pm 0.24$ & $7.92 \pm 0.32$ & 0.25 & $5.34 \pm 0.12$ & $5.39 \pm 0.07$ & $5.40 \pm 0.05$ & 0.88 \\
\hline $2 \mathrm{~h}$ glucose $(\mathrm{mmol} / \mathrm{l})$ & n.a. & n.a. & n.a. & & $5.47 \pm 0.22$ & $5.27 \pm 0.12$ & $5.19 \pm 0.16$ & 0.35 \\
\hline FPI (pmol/l) & $17.7 \pm 4.0$ & $15.2 \pm 1.0$ & $15.8 \pm 1.7$ & 0.26 & $13.5 \pm 1.3$ & $13.7 \pm 0.5$ & $14.3 \pm 1.0$ & 0.88 \\
\hline HOMA IR & $5.15 \pm 0.66$ & $5.04 \pm 0.39$ & $5.14 \pm 0.51$ & 0.79 & $3.35 \pm 0.43$ & $3.31 \pm 0.16$ & $3.49 \pm 0.27$ & 0.76 \\
\hline
\end{tabular}

Data are means \pm SEM. a Differences in genotype and allele ( $p$ value) distributions were tested by Fisher's exact tests. $p$ values represent values obtained after linear regression analysis with correction for age, sex and BMI 
AGT) and Lys4031 (Lys-Arg, AAG-AGG). The gene variants at Gly673 and Asp2674 and at Arg2828 and Leu4060 were in complete linkage disequilibrium with each other $(n=179$ and $n=95$ respectively). Gene variants at position Asp2678 and Asn3815 were not detected in our cohorts. Therefore we limited our studies to the gene variants at positions Asp2674, Arg2828 and Lys4031, which were subsequently studied in detail in the association studies (Table 1). Genotypes were determined by PCR-RFLP based methods in each individual after validation of the detection method by direct sequencing.

The observed frequencies were all in Hardy-Weinberg equilibrium (data not shown). Genotype and allele frequencies were not significantly different between patients and control subjects for either of the gene variants (All $p>0.2$, Table 1). Furthermore we did not observe significant associations with other parameters like BMI, glucose or insulin concentrations during OGTT (All $p>0.05$, Table 1). Insulin resistance as calculated by the HOMA insulin resistance index (HOMA IR) was also not significantly different between the different genotypes $(p>0.3$, Table 1$)$. Trends observed in the initial cohort could not be replicated in an independent population-based sample from the Rotterdam study (Type 2 DM, $n=95$ and NGT, $n=188$, data not shown) [5]. A priori power calculations showed that we had an 80 percent power to detect differences in allele frequency around 10 percent. We have also reconstructed haplotype combinations of the different gene variants using the PHASE v1.0 program [6]. We observed six different haplotype combinations, however; they were not significantly different between the cases and controls $(p>0.2$, data not shown). Also the reconstructed haplotypes did not associate with diabetes related parameters (data not shown).

This report describes association studies with gene variants in the coding region of the ALMS1 gene in Type 2 diabetes. The absence of significant associations suggest that the variants observed in our studies are not major factors in the pathogenesis of Type 2 diabetes mellitus or obesity. Furthermore we found no evidence for a disease-associated haplotype. We conclude that known gene variants in the coding regions of the ALMS1 gene are not associated with Type 2 diabetes, BMI or other diabetes related parameters in a population based study in The Netherlands. Further studies in other (larger) cohorts and with gene variants in other parts of this large gene locus are necessary to fully investigate the role of this gene in the pathogenesis of Type 2 diabetes mellitus and/or obesity.
Acknowledgements. The authors would like to thank the participants for their cooperation. The work was in part supported by a grant from the Dutch Diabetes Foundation (DFN).

L. M. 't Hart, J. A. Maassen

Department of Molecular Cell Biology, Leiden University Medical Center, Leiden, The Netherlands

J. M. Dekker, R. J. Heine, J. A. Maassen

On behalf of the Hoorn study, VU University Medical Center, Institute for Research in Extramural Medicine (EMGO), Amsterdam, The Netherlands

\section{References}

1. Collin GB, Marshall JD, Ikeda A et al. (2002) Mutations in ALMS1 cause obesity, type 2 diabetes and neurosensory degeneration in Alstrom syndrome. Nat Genet 31:74-78

2. Hearn T, Renforth GL, Spalluto C et al. (2002) Mutation of ALMS1, a large gene with a tandem repeat encoding 47 amino acids, causes Alstrom syndrome. Nat Genet 31:7983

3. Mooy JM, Grootenhuis PA, Vries H de et al. (1995) Prevalence and determinants of glucose intolerance in a Dutch Caucasian population. The Hoorn study. Diabetes Care 18:1270-1273

4. Botstein D, Risch N (2003) Discovering genotypes underlying human phenotypes: past successes for mendelian disease, future approaches for complex disease. Nat Genet 33 [Suppl]:228-237

5. Hofman A, Grobbee DE, Jong PTVM de et al. (1991) Determinants of disease and disability in the elderly: the Rotterdam elderly study. Eur J Epidemiol 7:403-422

6. Stephens M, Smith NJ, Donnelly P(2001) A new statistical method for haplotype reconstruction from population data. Am J Hum Genet 68:978-989

Corresponding author: Dr. J. A. Maassen, On behalf of the Hoorn study, VU University Medical Center, Institute for Research in Extramural Medicine (EMGO), Amsterdam, The Netherlands

E-mail: j.a.maassen@lumc.nl

\section{Autoantibodies in Type 1 and Type 2 diabetes in the Old Order Amish of Lancaster County, Pennsylvania}

To the editor: Autoantibodies to IA-2 (IA-2A) and GAD (GADA) have been widely used to identify individuals with Type 1 diabetes [1]. Up to $90 \%$ of newly diagnosed Type 1 patients have IA-2A and/or GADA. The number of Type 2 patients

$\overline{\text { DOI } 10.1007 / \mathrm{s} 00125-003-1139-\mathrm{z}}$

Received: 14 February 2003 / Revised: 8 April 2003

Published online: 18 June 2003

(C) Springer-Verlag 2003 with these autoantibodies is considerably lower, usually between 2 to $4 \%$ for IA-2 and 5 to $10 \%$ for GAD. Of non-diabetic control populations $1 \%$ or less have these autoantibodies.

Autoantibodies are of particular interest in genetically homogenous populations as in Finland [2] and Sardinia [3] since they could provide epidemiological and mechanistic insights into the role of these antibodies in the pathogenesis of diabetes. Such a genetically unique population also exists in the United States. The Old Order Amish emigrated from Western Europe to the United States at the beginning of the 18th century, approximately 200 families settled in Lancaster county, Pennsylvania [4]. The Old Order Amish are a genetically isolated and well-defined closed Caucasian population, with a high degree of consanguinity, and virtually no outsiders marrying into the community. Type 2 diabetes has been studied in this population [4], but autoimmune diabetes has not been examined. 